\title{
Tapentadol immediate release: a new treatment option for acute pain management
}

This article was published in the following Dove Press journal:

Journal of Pain Research

7 February 2010

Number of times this article has been viewed

\section{Marc Afilalo' \\ Jens-Ulrich Stegmann ${ }^{2}$ David Upmalis ${ }^{3}$}

'Sir Mortimer B. Davis Jewish General Hospital, Montréal, Canada; ${ }^{2}$ Global Drug Safety, Grünenthal $\mathrm{GmbH}$, Aachen, Germany; ${ }^{3}$ Johnson \& Johnson Pharmaceutical Research and Development, L.L.C., Raritan, New Jersey, USA
Correspondence: Marc Afilalo Associate Professor, McGill University, Director, Emergency Department, Sir Mortimer B. Davis Jewish General Hospital, 3755 Côte-St-Catherine Road, D-010, Montréal Québec H3T IE2 Canada

$\mathrm{Tel}+\mathrm{I}(5 \mathrm{I}$ ) 340-8222 (Ext 5568)

Fax +I (5I4) 340-75I9

Email marc.afilalo@mcgill.ca

\begin{abstract}
The undertreatment of acute pain is common in many health care settings. Insufficient management of acute pain may lead to poor patient outcomes and potentially life-threatening complications. Opioids provide relief of moderate to severe acute pain; however, therapy with pure $\mu$-opioid agonists is often limited by the prevalence of side effects, particularly opioid-induced nausea and vomiting. Tapentadol is a novel, centrally acting analgesic with 2 mechanisms of action, $\mu$-opioid receptor agonism and norepinephrine reuptake inhibition. The analgesic effects of tapentadol are independent of metabolic activation and tapentadol has no active metabolites; therefore, in theory, tapentadol may be associated with a low potential for interindividual efficacy variations and drug-drug interactions. Previous phase 3 trials in patients with various types of moderate to severe acute pain have shown that tapentadol immediate release (IR; 50 to $100 \mathrm{mg}$ every 4 to 6 hours) provides analgesia comparable to that provided by the pure $\mu$-opioid agonist comparator, oxycodone $\mathrm{HCl}$ IR (10 or $15 \mathrm{mg}$ every 4 to 6 hours), with a lower incidence of nausea, vomiting, and constipation. Findings suggest tapentadol may represent an improved treatment option for acute pain.
\end{abstract}

Keywords: tapentadol IR, acute pain, opioid, gastrointestinal tolerability

\section{Introduction}

Appropriate management of acute pain remains a considerable challenge for health care providers. Unrelieved acute pain may cause anxiety, sleep disturbances, and demoralization and may interfere with mental activity and social interactions. ${ }^{1,2}$ Acute pain can also increase heart rate and blood pressure, suppress immune functioning, and reduce pulmonary function, leading to an increased risk of dangerous complications, including myocardial ischemia, deep vein thrombosis, pulmonary embolism, hypoxia, pneumonia, and stroke. ${ }^{2}$ In addition to these more severe adverse effects, uncontrolled acute pain is also associated with gastrointestinal effects, including the development of ileus, nausea, and vomiting. ${ }^{3}$

The psychologic and physiologic effects of uncontrolled acute pain can result in longer hospital stays and unscheduled readmissions following surgery. ${ }^{4,5}$ A retrospective analysis of the medical records of 20,817 patients who had undergone same-day surgery in 1999 found that pain was the most common reason that patients were hospitalized immediately after surgery or returned to the hospital within 30 days of surgery, accounting for $38 \%$ of unscheduled postoperative hospital admissions or readmissions. ${ }^{4}$ In addition, prolonged acute pain can cause sensitization of the central and peripheral nervous systems, leading to the development of chronic pain, which is often difficult and costly to treat. ${ }^{6-8}$ submit your manuscript | www.dovepress.com

Dovepress
Journal of Pain Research 2010:3 I-9

(C) 2010 Afilalo et al, publisher and licensee Dove Medical Press Ltd. This is an Open Access article which permits unrestricted noncommercial use, provided the original work is properly cited. 
Although guidelines have been developed to improve acute pain management, ${ }^{9,10}$ pain relief remains suboptimal for many patients. ${ }^{11-16}$ Surveys conducted among patients who had undergone ambulatory surgery indicated that $30 \%{ }^{15}$ to $40 \%{ }^{12}$ of patients experience moderate to severe pain following discharge. Among hospitalized patients who were receiving treatment in various medical wards ${ }^{14}$ or who had undergone surgery, ${ }^{11}$ the percentages were even higher, with $52 \%{ }^{14}$ to $80 \%{ }^{11}$ of patients experiencing acute pain; of these patients, as many as $86 \%$ experienced moderate to extreme pain. ${ }^{11}$ The undertreatment of acute pain may result from several contributing factors related to patient care, such as infrequent pain assessments, underestimation of the severity of pain, concerns about side effects associated with analgesic treatment, and delays or dose reductions in the administration of analgesics by health care providers. ${ }^{13,14,17-20}$ In addition, patients may underreport acute pain because of low expectations of pain relief and concerns about the adverse effects of analgesic treatment. ${ }^{19,21}$ A 2004 survey of patients undergoing major abdominal surgery found that many patients were willing to sacrifice pain relief for a reduction in the severity of side effects. ${ }^{22}$

Current treatment options for the management of acute pain include opioid analgesics (eg, morphine, hydromorphone, and oxycodone) and nonopioid analgesics (eg, acetaminophen, acetylsalicylic acid, and nonsteroidal anti-inflammatory drugs [NSAIDs]). ${ }^{23}$ Most NSAIDs are limited by a therapeutic ceiling and are appropriate for the relief of only mild to moderate pain. ${ }^{23}$ In addition, NSAIDs are contraindicated in patients with peptic ulcer disease, renal impairment, and any tendency for bleeding. ${ }^{24}$ Cyclooxygenase-2 (COX-2)-specific inhibitors do not impair platelet function and have an improved gastrointestinal tolerability profile relative to other NSAIDs ${ }^{25}$; however, certain COX-2-specific inhibitors have been linked to an increase in the risk of cardiovascular side effects, including myocardial infarction. ${ }^{26}$

Opioids are typically used for the management of moderate to severe acute pain, ${ }^{27}$ but opioid use is limited by the occurrence of a range of side effects. ${ }^{28}$ Opioids exert their analgesic effects primarily through agonistic interactions with $\mu$-opioid receptors in neurons in the pain pathway, which lead to a reduction in neurotransmitter release and associated pain. ${ }^{29}$ However, the agonistic interactions responsible for opioid activity are not limited to neurons of the pain pathway. ${ }^{23}$ Opioid receptors are present throughout the nervous system, and the interactions of opioids with nonanalgesic receptors are responsible for many of the side effects associated with opioid treatment. ${ }^{23}$ For example, opioids may induce nausea and vomiting by direct stimulation of receptors at the chemoreceptor trigger zone and vestibular apparatus. $^{30}$

A systematic review ${ }^{31}$ of randomized controlled trials of opioids in postoperative patients found that the most common side effects occurring in these patients were gastrointestinal side effects, central nervous system (CNS) side effects, pruritus, and urinary retention. Pruritus occurred in $18.3 \%$ of patients who were treated with opioids following surgery and was most common with epidural administration of opioids. ${ }^{31}$ Somnolence and sedation were the most commonly reported CNS side effects; the incidence of somnolence ranged from less than $2 \%$ to more than $90 \%$, depending on the route of administration and type of opioid used. ${ }^{31}$ Gastrointestinal side effects, including nausea, vomiting, and constipation, were the most common side effects associated with opioid analgesia and were reported by $31.0 \%$ of patients. ${ }^{31}$ Opioid-induced postoperative nausea and vomiting (PONV) is associated with negative effects on patient outcomes and quality of life, ${ }^{32}$ which may lead to increases in recovery time, duration of hospitalization, and cost of medical care. ${ }^{33,34}$ The underuse of opioid analgesics by health care providers to relieve acute pain may be related to attempts to balance analgesia against concerns about opioid-induced side effects and subsequent deleterious repercussions for patient outcomes. ${ }^{20}$

There is a continuing need for a potent analgesic agent that will provide adequate relief of acute pain, but with a reduction in side effects. Tapentadol is a novel, centrally acting analgesic that offers analgesic efficacy that is similar to that provided by a pure $\mu$-opioid agonist comparator, but with an improved side effect profile, which may represent a significant advancement in the management of moderate to severe acute pain.

\section{Pharmacology and pharmacokinetics of tapentadol}

Tapentadol (Figure 1) is a centrally acting analgesic with 2 complementary mechanisms of action, $\mu$-opioid receptor agonism and norepinephrine reuptake inhibition. ${ }^{35,36}$ In opioid receptor binding studies, tapentadol was found to have only a modest affinity (dissociation constant $\left.\left[\mathrm{K}_{\mathrm{i}}\right]=0.096 \mu \mathrm{M}[\mathrm{rat}]\right)^{35}$ for the $\mu$-opioid receptor relative to pure $\mu$-opioid receptor agonists such as oxycodone $\left(\mathrm{K}_{\mathrm{i}}=0.018 \mu \mathrm{M}\right.$ [rat $\left.]\right)$ or morphine $\left(\mathrm{K}_{\mathrm{i}}=0.002 \mu \mathrm{M}[\mathrm{rat}]\right) .{ }^{37} \mathrm{~A}$ similar binding affinity to that observed in native rat receptors was demonstrated for tapentadol at the human recombinant $\mu$-opioid receptor $\left(\mathrm{K}_{\mathrm{i}}=0.16 \mu \mathrm{M}\right.$ [human]). ${ }^{35}$ Despite the approximately 50 -fold difference in binding affinity for the $\mu$-opioid receptor relative to morphine, tapentadol demonstrated only a 2- to 3-fold reduction in analgesic potency in a series of acute and persistent animal 


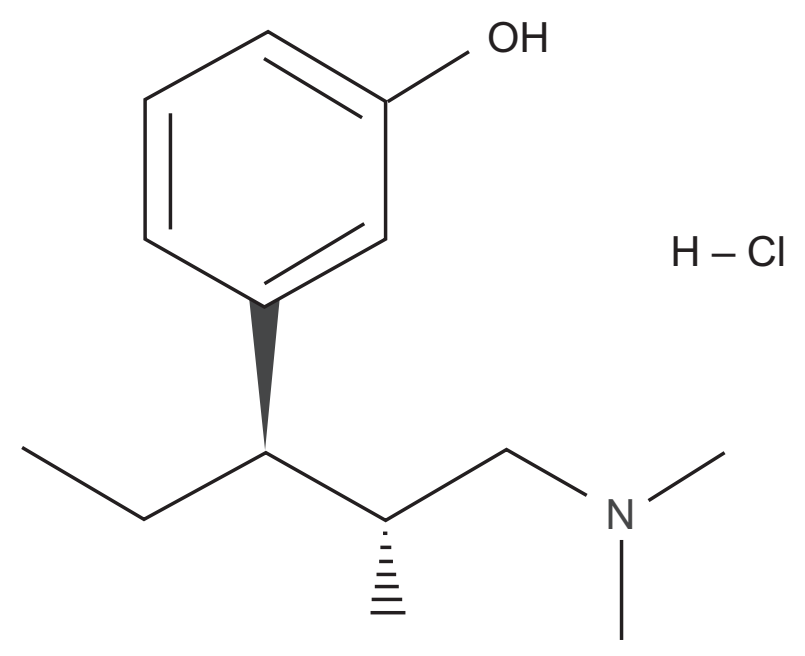

Figure I Chemical structure of tapentadol $\mathrm{HCl}$.

pain models. ${ }^{36}$ This disparity in potency and binding affinity for the $\mu$-opioid receptor may be related to the contribution of the second mechanism of action, inhibition of norepinephrine reuptake, to the analgesic effects of tapentadol. In rat synaptosomal reuptake assays, tapentadol inhibited the norepinephrine reuptake transporter with a $\mathrm{K}_{\mathrm{i}}$ of $0.48 \pm 0.11 \mu \mathrm{M}$ and, when administered in intraperitoneal doses of 4.64 to $10 \mathrm{mg} / \mathrm{kg}$, produced a dose-dependent increase in extracellular levels of norepinephrine in the ventral hippocampus of freely moving rats to a maximum of $450 \%$ above baseline with $10 \mathrm{mg} / \mathrm{kg}$, as measured by microdialysis. ${ }^{35}$ In contrast to tapentadol, morphine administered to rats in intraperitoneal doses of 1 to $10 \mathrm{mg} / \mathrm{kg}$ produced a small, nonsignificant decrease in extracellular norepinephrine levels. ${ }^{35}$

The contributions of both $\mu$-opioid receptor agonism and norepinephrine reuptake inhibition to the analgesic effects of tapentadol were further elucidated by examining the extent to which analgesia was blocked by the selective $\mu$-opioid receptor antagonist naloxone and the norepinephrine $\alpha_{2}$-receptor antagonist yohimbine. ${ }^{35}$ In an animal model ${ }^{35}$ of acute (writhing) pain, it was observed that intravenous tapentadol and morphine induced dose-dependent inhibition of writhing $\left(\mathrm{ED}_{50}\right.$ for tapentadol, $0.7 \mathrm{mg} / \mathrm{kg} ; \mathrm{ED}_{50}$ for morphine, $0.4 \mathrm{mg} / \mathrm{kg}$ ). When combined with naloxone, the antinociceptive effect of morphine $(0.681 \mathrm{mg} / \mathrm{kg})$ was more potently reduced than that of tapentadol $(3.16 \mathrm{mg} / \mathrm{kg})$; the $\mathrm{ED}_{50}$ for naloxone antagonism was $0.007 \mathrm{mg} / \mathrm{kg}$ when combined with morphine and $0.099 \mathrm{mg} / \mathrm{kg}$ when combined with tapentadol $(P<0.001$ for tapentadol vs morphine). In a spinal nerve ligation model of mononeuropathic pain, ${ }^{35}$ coadministration of intraperitoneal naloxone $(0.3 \mathrm{mg} / \mathrm{kg})$ with equianalgesic intravenous doses of tapentadol $(10 \mathrm{mg} / \mathrm{kg})$ or morphine $(6.81 \mathrm{mg} / \mathrm{kg})$ reduced the anti-allodynic effect of tapentadol from $72 \%$ to $42 \%$ of the maximal possible effect (MPE); the anti-allodynic effect of morphine was reduced from $83 \%$ to $25 \%$ of the MPE. In contrast, when yohimbine $(2.15 \mathrm{mg} / \mathrm{kg})$ was administered intraperitoneally in combination with intravenous doses of morphine $(6.81 \mathrm{mg} / \mathrm{kg})$ or tapentadol $(10 \mathrm{mg} / \mathrm{kg})$, the anti-allodynic effect of tapentadol was reduced from $81 \%$ to $19 \%$ of the MPE, whereas the antiallodynic effect of morphine was only minimally reduced (from $80 \%$ to $54 \%$ of the MPE) ${ }^{35}$ These results indicate that both $\mu$-opioid receptor agonist and norepinephrine reuptake inhibitor mechanisms are involved in the analgesic effect of tapentadol and that, in contrast to morphine, norepinephrine reuptake inhibition plays a prominent role in tapentadolinduced analgesia.

In addition to contributing to the analgesic activity of tapentadol, the opioid-sparing effect of norepinephrine reuptake inhibition may also contribute to a reduction of adverse effects associated with pure $\mu$-opioid agonists. ${ }^{36}$ Such an opioid-sparing effect has been achieved by combining other analgesics, such as NSAIDs or COX-2-specific inhibitors, with opioids to control acute pain. ${ }^{38}$ This type of multimodal strategy achieves an additive analgesic effect by combining 2 different mechanisms of analgesic activity, but reduces the consumption of opioid analgesics and, thereby, the incidence of adverse effects associated with $\mu$-opioid agonist activity. ${ }^{38}$ For example, in a study of 200 patients undergoing outpatient anterior cruciate ligament surgery, patients who received perioperative doses of the COX-2-specific inhibitor celecoxib in addition to oxycodone experienced less pain $(P<0.01)$ in the recovery room, had lower postoperative opioid consumption $(P<0.001)$, and reported a lower incidence of PONV $(P<0.05)$ than patients taking oxycodone alone..$^{39}$ By combining a second mechanism of analgesic activity with $\mu$-opioid receptor agonism, tapentadol may offer the benefits of multimodal analgesia within a single molecule.

The analgesic effects of tapentadol are independent of metabolic activation, and tapentadol has no active metabolites. ${ }^{40}$ Orally administered tapentadol is principally cleared by hepatic glucuronidation via the uridine $5^{\prime}$-diphospho-glucuronosyl transferases (UGTs) UGT1A9 and UGT2B7, which are responsible for approximately $55 \%$ of tapentadol metabolism in humans. ${ }^{41}$ The major metabolite of tapentadol, tapentadol$O$-glucuronide, has no activity at opioid receptors, synaptosomal reuptake systems, or other binding sites. ${ }^{35}$ Morphine is likewise primarily metabolized by hepatic glucuronidation via UGT2B7 to morphine-3-glucuronide (M3G) and morphine6-glucuronide (M6G). ${ }^{42}$ Morphine-3-glucuronide has no 
analgesic activity, but M6G has an affinity for the $\mu$-opioid receptor and contributes significantly to the analgesic effect of morphine. ${ }^{43}$ In patients with renal insufficiency, M6G accumulates and may contribute to the higher incidence of morphine toxicity observed in these patients. ${ }^{44,45}$

Many other opioids, including oxycodone, codeine, dihydrocodeine, hydrocodone, and tramadol, are primarily metabolized by the cytochrome P450 (CYP) enzymes CYP2D6 or CYP3A4. ${ }^{46}$ Mutations in the CYP2D6 gene, which occur in approximately $1 \%$ to $7 \%$ of the Caucasian population, can either decrease or increase enzyme activity, leading to alterations in opioid analgesia. ${ }^{47}$ The analgesic effects of codeine are highly dependent on conversion of codeine to morphine by CYP2D6; a poor CYP2D6 metabolic phenotype can suppress codeine analgesia, and an ultra-rapid CYP2D6 metabolic phenotype can lead to increased opioid effects, such as euphoria, dizziness, and visual disturbances. ${ }^{47}$

In addition to the potential for varied individual responses to cytochrome P450-metabolized opioids due to genetic mutations, opioids metabolized by the cytochrome $\mathrm{P} 450$ pathway are associated with an increased risk for drug-drug interactions. More than half of all drugs are metabolized by CYP3A4, and opioids metabolized by this isozyme (including fentanyl, buprenorphine, and methadone) are prone to drug-drug interactions with antiretroviral agents and antidepressants. ${ }^{48}$ Opioids metabolized by CYP2D6, including codeine, dihydrocodeine, and oxycodone, are also associated with a number of drug-drug interactions. Substrates of CYP2D6 include antiarrhythmic agents, antidepressants, antipsychotics, antiparasitic agents, and tamoxifen. ${ }^{48}$ The analgesic activity of codeine is particularly impaired by inhibition of CYP2D6 because the analgesic effects of codeine result from the formation of metabolites, including morphine and, possibly, codeine-6-glucuronide. ${ }^{48}$

In vitro studies ${ }^{41}$ were used to evaluate the inhibitory or inducing effects of tapentadol on the 7 major CYP isoforms involved in drug metabolism (CYP2D6, CYP3A4, CYP1A2, CYP2A6, CYP2C9, CYP2C19, and CYP2E1). Tapentadol did not undergo significant metabolism by CYP enzymes and did not inhibit or induce the activity of any of the CYP isoforms tested, with the exception of CYP2D6. ${ }^{41}$ Limited inhibition of CYP2D6 was observed with tapentadol, with competitive inhibition occurring with a $\mathrm{K}_{\mathrm{i}}$ of $181 \mu \mathrm{M}$ and noncompetitive inhibition with a $\mathrm{K}_{\mathrm{i}}$ of $1,410 \mu \mathrm{M} .{ }^{41}$ The $\mathrm{K}_{\mathrm{i}}$ values for both competitive and noncompetitive inhibition are much higher than the expected tapentadol plasma concentrations of 0.5 to $1 \mu \mathrm{M}$ (following therapeutic dosing), indicating that CYP2D6 inhibition by tapentadol is unlikely to be clinically relevant. ${ }^{41}$
Two randomized, open-label studies were performed to evaluate the potential for drug-drug interactions between tapentadol and 3 common analgesics that, like tapentadol, are metabolized by UGT pathways (acetaminophen, naproxen, and acetylsalicylic acid). ${ }^{49}$ Mean serum concentrations of tapentadol and tapentadol-O-glucuronide were similar after administration of tapentadol IR alone and after coadministration with acetaminophen and acetylsalicylic acid. A slight increase in the serum concentration of tapentadol and a slight decrease in the serum concentration of tapentadol-O-glucuronide were observed after coadministration with naproxen, but these changes were not considered clinically relevant, due to the relatively small magnitude of change. Thus, no dosing adjustments are needed for administration of tapentadol with any of these commonly coadministered analgesics.

\section{Tapentadol IR for moderate to severe pain}

The efficacy of tapentadol IR for the relief of moderate to severe pain has been evaluated in 3 randomized, double-blind, phase 3 studies in patients with postoperative (bunionectomy) pain ${ }^{50,51}$ and pain related to end-stage degenerative joint disease ${ }^{52}$ and as a secondary measure in a phase 3 randomized, doubleblind, 90-day safety study. ${ }^{53}$ In one of the postoperative pain studies, ${ }^{51}$ patients received tapentadol IR $(50,75$, or $100 \mathrm{mg})$, oxycodone $\mathrm{HCl}$ IR (15 mg), or placebo every 4 to 6 hours for 72 hours following bunionectomy; in the other postoperative pain study, ${ }^{50}$ patients received tapentadol IR (50 or $75 \mathrm{mg}$ ), oxycodone $\mathrm{HCl}$ IR (10 mg), or placebo every 4 to 6 hours for 72 hours following bunionectomy. In the end-stage joint disease study, ${ }^{52}$ patients received tapentadol IR (50 or $75 \mathrm{mg}$ ), oxycodone $\mathrm{HCl}$ IR (10 mg), or placebo every 4 to 6 hours for 10 days. In the 90 -day safety study, ${ }^{53}$ patients received flexible doses of tapentadol IR 50 or $100 \mathrm{mg}$ (up to $600 \mathrm{mg} /$ day) or oxycodone $\mathrm{HCl} 10 \mathrm{mg}$ or $15 \mathrm{mg}$ (up to $90 \mathrm{mg}$ /day) every 4 to 6 hours as needed for up to 90 days.

In all 4 phase 3 studies $^{50-53}$ of tapentadol IR for acute pain, improvements in pain intensity were observed with tapentadol IR treatment (50,75, or $100 \mathrm{mg}$ every 4 to 6 hours) that were similar to those observed with oxycodone $\mathrm{HCl}$ IR treatment (10 or $15 \mathrm{mg}$ every 4 to 6 hours) based on pain intensity measurements on an 11-point numerical rating scale (NRS; $0=$ "no pain" to $10=$ "worst pain imaginable"). For example, in the postoperative pain study ${ }^{50}$ in which patients received tapentadol IR (50 or $75 \mathrm{mg}$ ) for 72 hours following bunionectomy, 901 patients were randomized to treatment. In that study, ${ }^{50}$ efficacy was evaluated based on the following measures: the sum of the pain intensity difference (SPID) over 
the first 12, 24, 48 (primary efficacy endpoint), and 72 hours of treatment; responder rates at 48 hours; and the patient global impression of change (PGIC). Based on increases in the mean (SD) $\mathrm{SPID}_{48}$, significantly greater reductions in pain intensity from baseline were observed with tapentadol IR $50 \mathrm{mg}$ (122.2 [98.66]), tapentadol IR $75 \mathrm{mg}$ (143.7 [96.52]), and oxycodone $\mathrm{HCl}$ IR $10 \mathrm{mg}$ (140.3 [99.52]) than with placebo (54.1 [105.74]; $P<0.001$ for all comparisons; Figure 2). Additionally, the efficacy of both doses of tapentadol IR was noninferior to the efficacy of oxycodone $\mathrm{HCl}$ IR $10 \mathrm{mg}$, based on the lower bounds of the 2-sided $97.5 \%$ confidence intervals for tapentadol IR $50 \mathrm{mg}(-36.05)$ and $75 \mathrm{mg}(-12.91)$, which were within the prespecified noninferiority margin of -48 ( $10 \%$ of the total possible value).

Secondary efficacy measurements supported the results of the primary efficacy endpoint in this phase 3 postoperative pain study.$^{50}$ Compared with placebo, significant reductions in pain intensity (based on the SPID) were observed for all active treatment groups at 12,24 , and 72 hours $(P<0.001$ for all comparisons; Figure 2).

The distribution of responder rates was also significantly different between both tapentadol IR dose groups and placebo $(P<0.001)$ and oxycodone $\mathrm{HCl}$ IR $10 \mathrm{mg}$ and placebo $(P<0.001$; Figure 3$)$. Compared with placebo, a significantly greater percentage of patients in all active treatment groups reported reductions in pain intensity at 48 hours of at least 30\% (tapentadol IR $50 \mathrm{mg}, 77.5 \%$; tapentadol IR $75 \mathrm{mg}$, 76.3\%; oxycodone HCl IR $10 \mathrm{mg}, 75.2 \%$; placebo, 58.0\%;
$P \leq 0.004$ for all comparisons) and at least $50 \%$ (tapentadol IR $50 \mathrm{mg}$, 64.7\%; tapentadol IR $75 \mathrm{mg}, 64.0 \%$; oxycodone $\mathrm{HCl}$ IR $10 \mathrm{mg}$, 64.4\%; placebo, 47.8\%; $P \leq 0.012$ for all comparisons).

For the PGIC, patients rated their overall status since beginning study medication on a 7-point scale ( $1=$ "very much improved" to $7=$ "very much worse"). At the end of the study or early discontinuation, a rating of "much improved" or "very much improved" on the PGIC was reported by $83 \%$ of patients in the tapentadol IR 50-mg group, $88 \%$ of patients in the tapentadol IR 75-mg group, $86 \%$ of patients in the oxycodone $\mathrm{HCl}$ IR 10 -mg group, and $65 \%$ of patients in the placebo group. The overall distribution of PGIC scores was significantly more favorable for all active treatment groups compared with placebo ( $P<0.001$ for all comparisons).

\section{Safety and tolerability of tapentadol IR}

In all 4 studies, ${ }^{50-53}$ the most commonly reported treatment emergent adverse events (TEAEs) for patients who received any dosage of tapentadol IR were typical of drugs with $\mu$-opioid agonist activity, and there were no major TEAEs suggestive of hyper-adrenergism. In the phase 3 study $^{50}$ of tapentadol IR 50 and $75 \mathrm{mg}$ in patients with postoperative pain following bunionectomy, the most common TEAEs (reported by $\geq 10 \%$ of patients in any treatment group) were nausea, vomiting, dizziness, headache, somnolence, pruritus, and constipation. Tapentadol IR $50 \mathrm{mg}$ was associated with

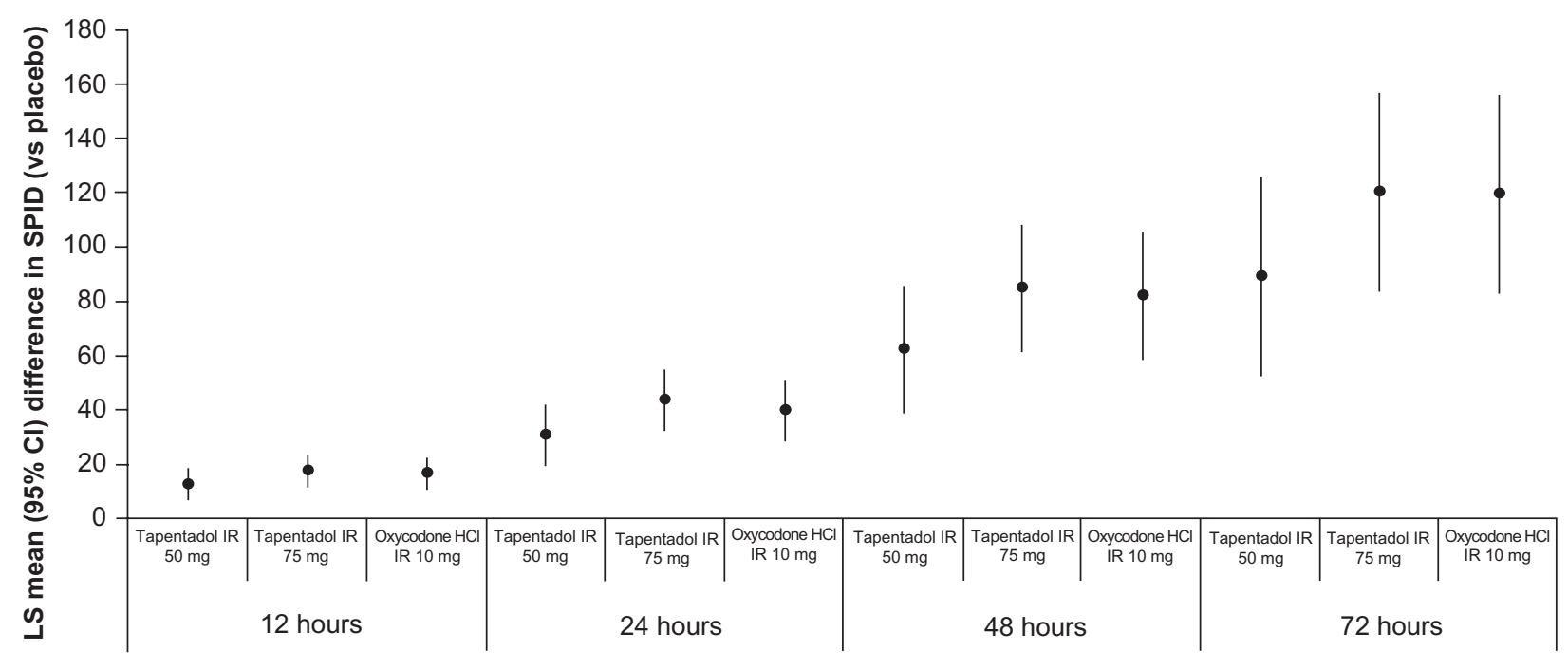

Figure 2 Differences from placebo in mean SPID scores at 12, 24, 48, and 72 hours in patients with moderate to severe pain following bunionectomy treated with tapentadol IR 50 or $75 \mathrm{mg}$ or oxycodone $\mathrm{HCl}$ IR $10 \mathrm{mg} .{ }^{50}$

aP $<0.001$ vs placebo for all comparisons.

Abbreviations: SPID, sum of pain intensity difference; LS, least squares; $\mathrm{Cl}$, confidence interval; IR, immediate release. 


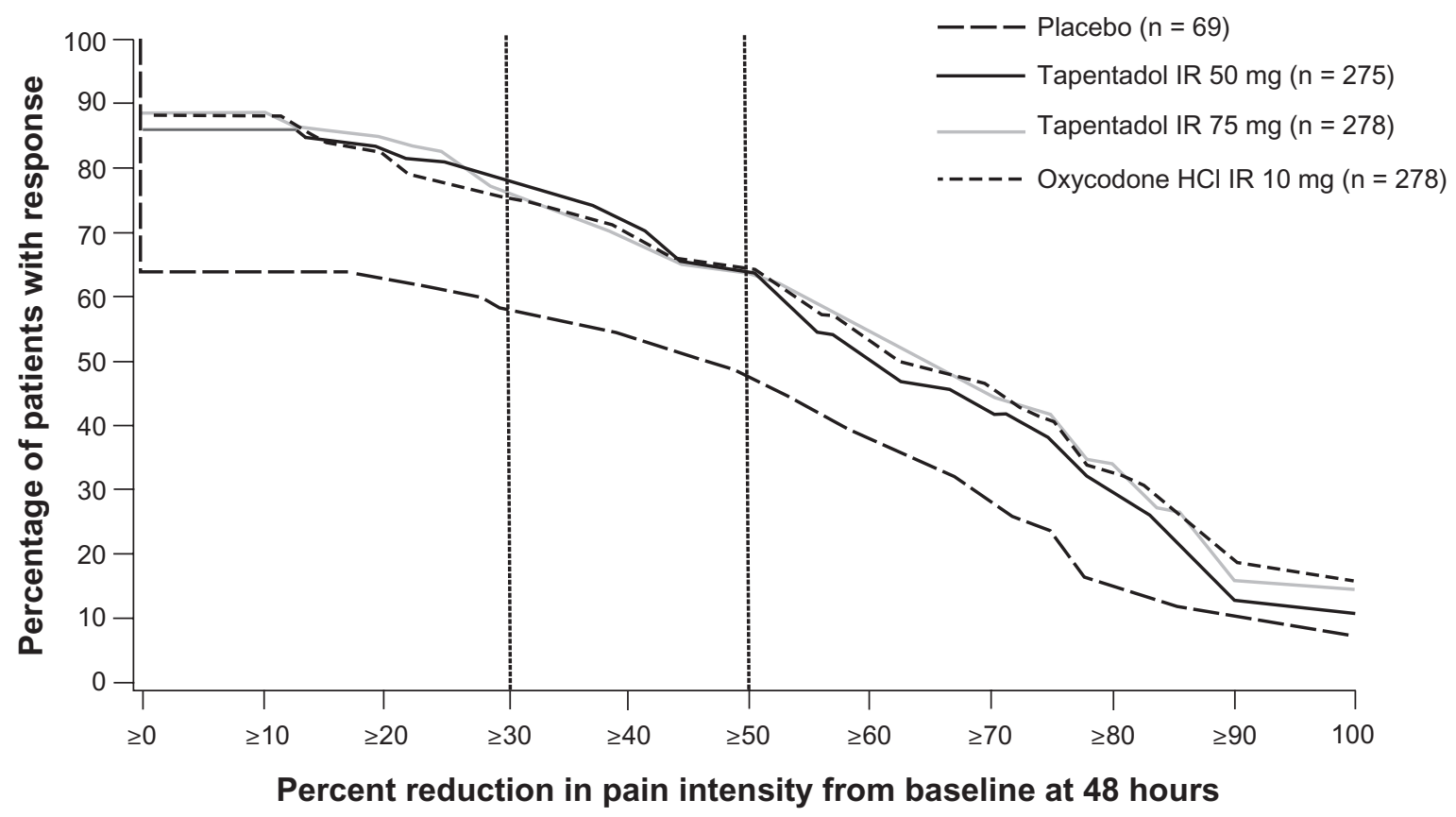

Figure 3 Distribution of responder rates based on pain intensity at 48 hours in patients with postoperative pain following bunionectomy. Reproduced from Daniels et al (2009). ${ }^{50}$ Copyright (C) 2009 Informa Healthcare.

Abbreviation: IR, immediate release.

a lower incidence of all of these TEAEs than oxycodone $\mathrm{HCl}$ IR $10 \mathrm{mg}$, and tapentadol IR $75 \mathrm{mg}$ was associated with a lower incidence of nausea, headache, and constipation than oxycodone HCl IR $10 \mathrm{mg}$ (Figure 4). A significantly lower percentage of patients reported nausea and/or vomiting in the tapentadol IR 50-mg group (35\%) than in the oxycodone $\mathrm{HCl}$ IR 10-mg group (59\%; $P<0.001)$. Thus, at a dose $(50 \mathrm{mg})$ that provided efficacy that was noninferior to that provided by oxycodone $\mathrm{HCl}$ IR $10 \mathrm{mg}$, tapentadol IR was associated with a significantly lower incidence of gastrointestinal adverse events than oxycodone IR. A lower percentage of patients in the tapentadol IR 75-mg (51\%) than in the oxycodone $\mathrm{HCl}$ IR 10-mg group (59\%) reported nausea and/or vomiting, but the difference did not reach statistical significance $(P=$ 0.057 ). A low percentage ( $<3 \%$ in any treatment group) of patients reported TEAEs that led to study discontinuation in the tapentadol IR 50-mg group (1.1\%), the tapentadol IR $75-\mathrm{mg}$ group (2.9\%), the oxycodone HCl IR $10-\mathrm{mg}$ group $(1.8 \%)$, and the placebo group (1.5\%).

The 90-day safety study ${ }^{53}$ permitted an evaluation of the long-term safety of flexible doses of tapentadol IR (50 or $100 \mathrm{mg}$ every 4 to 6 hours) in comparison with flexible doses of oxycodone $\mathrm{HCl}$ IR ( 10 or $15 \mathrm{mg}$ every 4 to 6 hours) in patients with acute osteoarthritis hip or knee pain or low back pain. Similar to the phase 3 postoperative pain study, ${ }^{50}$ the most common TEAEs (occurring in $\geq 10 \%$ of patients in either treatment group) included gastrointestinal TEAEs (nausea, vomiting, and constipation), nervous system TEAEs (dizziness, headache, and somnolence), and pruritus. A lower percentage of patients in the tapentadol IR group than in the oxycodone IR group reported nausea (18.4\% vs $29.4 \%)$, vomiting ( $16.9 \%$ vs $30.0 \%)$, constipation ( $12.8 \%$ vs $27.1 \%$ ), and pruritus ( $4.3 \%$ vs $11.8 \%)$. Odds ratios demonstrated that patients treated with tapentadol IR were significantly less likely than patients treated with oxycodone IR to report nausea (0.542), vomiting (0.476), the composite of nausea and/or vomiting (0.458), or constipation $(0.396 ; P<0.001$ for all comparisons). In addition, a lower percentage of patients discontinued from the study because of AEs in the tapentadol IR group (20.8\%) than in the oxycodone IR group (30.6\%), and patients in the oxycodone IR group discontinued significantly earlier than those in the tapentadol IR group (nominal $P<0.05$; Figure 5). The percentage of patients who discontinued from the study due to gastrointestinal AEs was lower in the tapentadol IR group (8.8\%) than in the oxycodone IR group (21.1\%).

Compared with placebo, tapentadol IR (50 to $100 \mathrm{mg}$ every 4 to 6 hours) and oxycodone HCl IR (10 or $15 \mathrm{mg}$ every 4 to 6 hours) were associated with a higher incidence of TEAEs at all doses studied, and the majority of TEAEs increased with increasing dose. ${ }^{50-52}$ However, tapentadol IR was associated with a reduction in TEAEs, particularly 


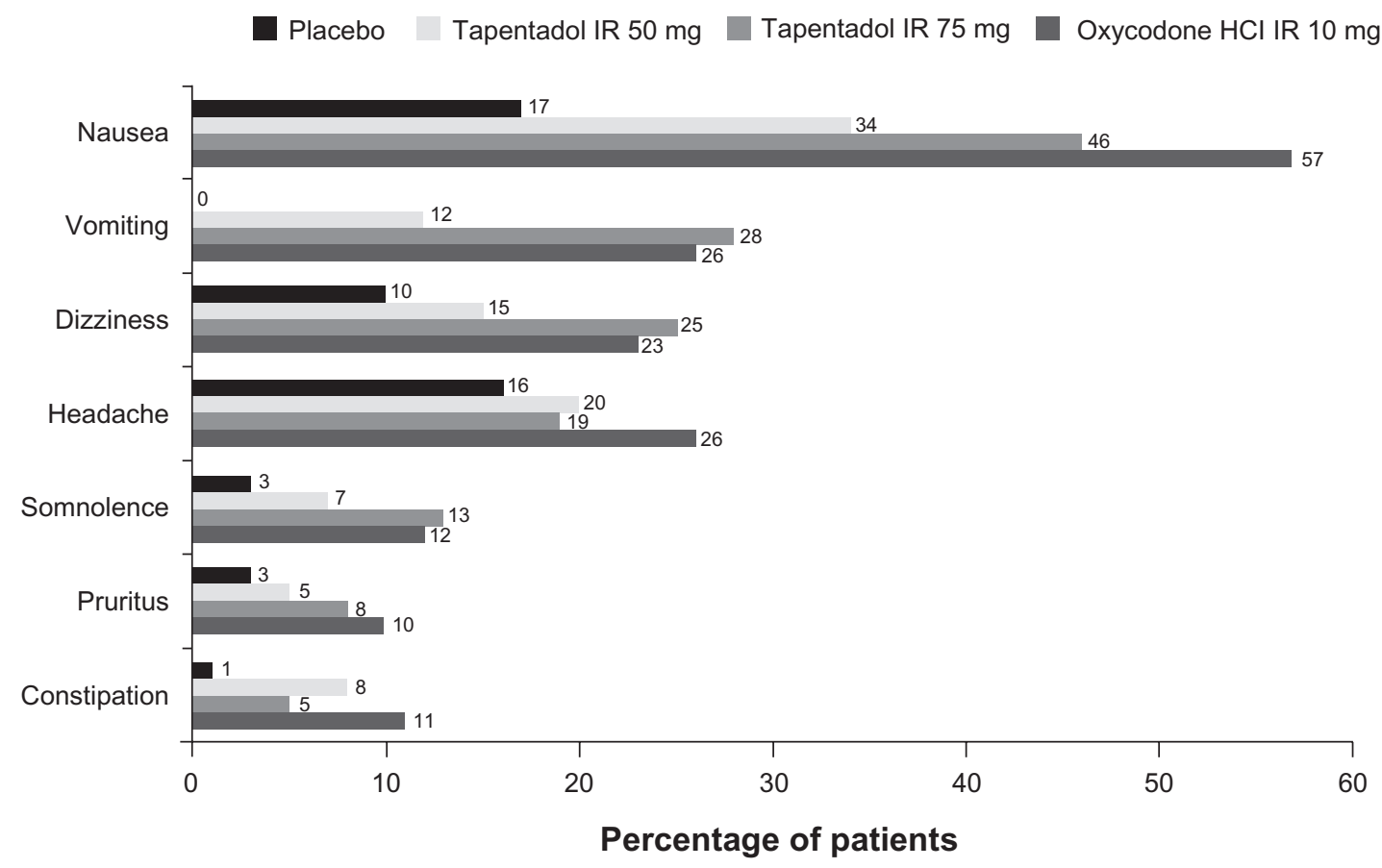

Figure 4 Treatment-emergent adverse events occurring in $\geq 10 \%$ of patients in any treatment group among patients treated with placebo, tapentadol IR 50 or $75 \mathrm{mg}$, or oxycodone $\mathrm{HCl}$ IR $10 \mathrm{mg}$ following bunionectomy. . $^{0}$ Abbreviation: IR, immediate release.

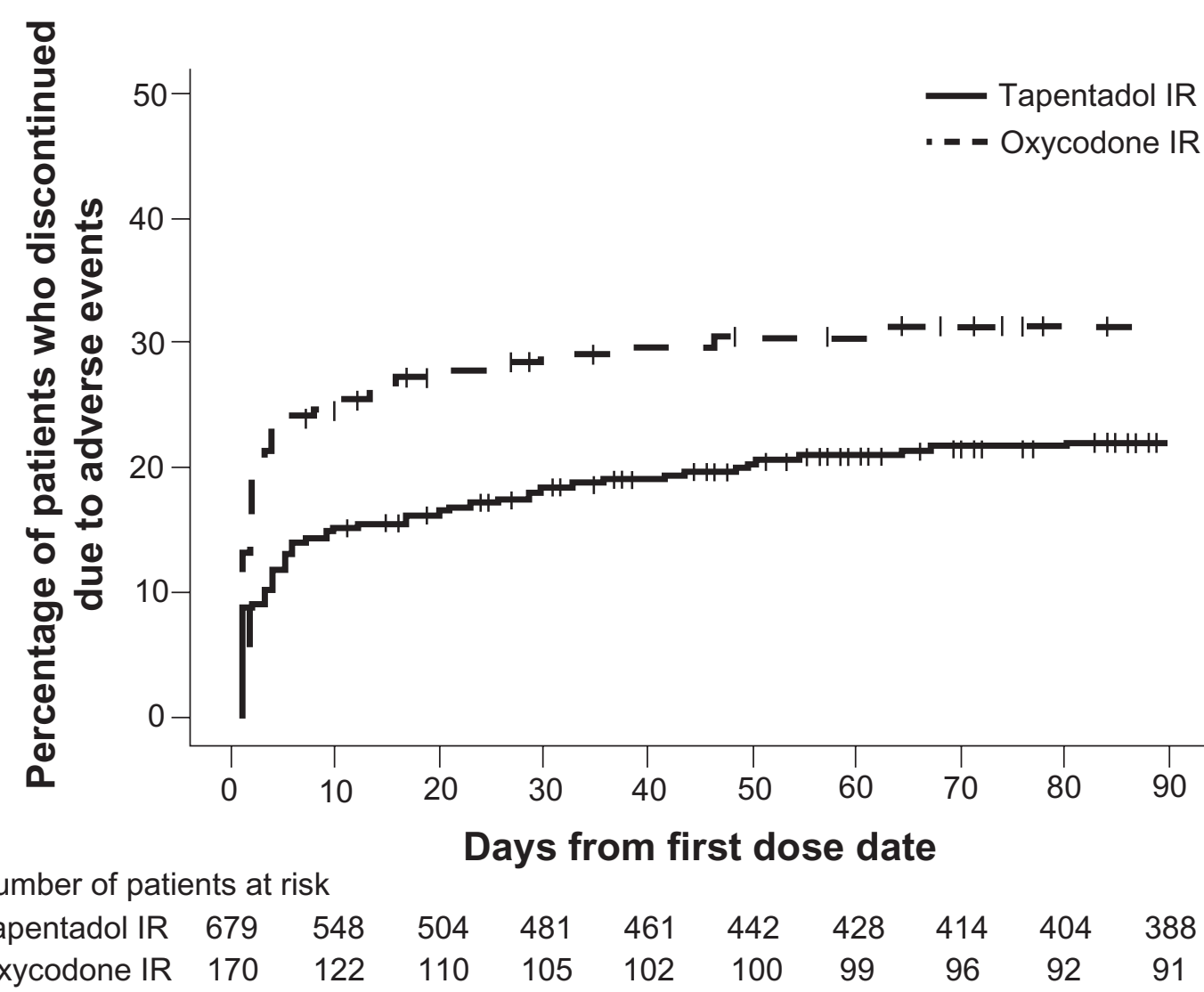

Figure 5 The distribution of times to discontinuation due to adverse events from the 90 -day safety study among patients with osteoarthritis hip or knee pain or low back pain treated with tapentadol IR or oxycodone IR. Reproduced from Hale et al (2009). ${ }^{53}$

Abbreviation: IR, immediate release. 
gastrointestinal TEAEs and pruritus, relative to oxycodone IR in all 4 phase 3 studies. ${ }^{50-53}$ The lower incidence of gastrointestinal TEAEs observed with tapentadol IR relative to oxycodone $\mathrm{IR}^{50-53}$ was associated with a lower percentage of patients who discontinued treatment because of TEAEs. Nausea and vomiting are often associated with the initiation of opioid therapy ${ }^{27}$ and are considered to be among the most undesirable adverse effects associated with analgesic therapy. ${ }^{54}$ These opioid-induced gastrointestinal TEAEs may be doselimiting and are often severe enough to cause patients to discontinue therapy, leading to disruption of pain relief. ${ }^{55,56}$

\section{Conclusions}

Tapentadol is a novel, centrally acting analgesic with 2 mechanisms of action, $\mu$-opioid receptor agonism and norepinephrine reuptake inhibition, ${ }^{35,36}$ which may contribute to an improved gastrointestinal tolerability profile. In patients with moderate to severe acute pain of various etiologies, tapentadol IR has been shown to offer comparable analgesia to that provided by oxycodone IR, with lower incidences of gastrointestinal adverse effects and pruritus and lower rates of discontinuation due to adverse effects. ${ }^{50-53}$ This combination of potent analgesia and tolerability may represent a substantial improvement over current acute pain relief strategies.

\section{Acknowledgments}

Editorial support for the writing of this manuscript was provided by Megan Knagge, PhD, of MedErgy, and was funded by Johnson \& Johnson Pharmaceutical Services, L.L.C. The authors were not compensated and retained full editorial control over the content of the manuscript.

\section{Disclosures}

D. Upmalis is an employee and shareholder of Johnson \& Johnson. J.-U. Stegmann is an employee of Grünenthal GmbH.

\section{References}

1. Breivik H. Postoperative pain management: why is it difficult to show that it improves outcome? Eur J Anaesthesiol. 1998;15(6):748-751.

2. MacIntyre P; on behalf of the Working Party of the Australian and New Zealand College of Anaesthetists. Acute pain management: scientific evidence, 2nd ed. Melbourne, Australia: Australian and New Zealand College of Anaesthetists, 2005. Available from: http://www.nhmrc.gov. au/publications/synopses/cp104syn.htm. Accessed October 30, 2009.

3. Spacek A. Modern concepts of acute and chronic pain management. Biomed Pharmacother. 2006;60(7):329-335.

4. Coley KC, Williams BA, DaPos SV, Chen C, Smith RB. Retrospective evaluation of unanticipated admissions and readmissions after same day surgery and associated costs. J Clin Anesth. 2002;14(5):349-353.

5. Gold BS, Kitz DS, Lecky JH, Neuhaus JM. Unanticipated admission to the hospital following ambulatory surgery. JAMA. 1989;262(21): 3008-3010.
6. Crombie IK, Davies HT, Macrae WA. Cut and thrust: antecedent surgery and trauma among patients attending a chronic pain clinic. Pain. 1998;76(1-2):167-171.

7. Macrae WA. Chronic pain after surgery. Br J Anaesth. 2001;87(1):88-98.

8. Taillefer MC, Carrier M, Belisle S, et al. Prevalence, characteristics, and predictors of chronic nonanginal postoperative pain after a cardiac operation: a cross-sectional study. J Thorac Cardiovasc Surg. 2006; 131(6): 1274-1280.

9. American Society of Anesthesiologists Task Force on Acute Pain Management. Practice guidelines for acute pain management in the perioperative setting. A report by the American Society of Anesthesiologists Task Force on Pain Management, Acute Pain Section. Anesthesiology. 1995;82(4):1071-1081.

10. American Society of Anesthesiologists Task Force on Acute Pain Management. Practice guidelines for acute pain management in the perioperative setting: an updated report by the American Society of Anesthesiologists Task Force on Acute Pain Management. Anesthesiology. 2004;100(6):1573-1581.

11. Apfelbaum JL, Chen C, Mehta SS, Gan TJ. Postoperative pain experience: results from a national survey suggest postoperative pain continues to be undermanaged. Anesth Analg. 2003;97(2):534-540.

12. Beauregard L, Pomp A, Choiniere M. Severity and impact of pain after day-surgery. Can J Anaesth. 1998;45(4):304-311.

13. Carroll KC, Atkins PJ, Herold GR, et al. Pain assessment and management in critically ill postoperative and trauma patients: a multisite study. Am J Crit Care. 1999;8(2):105-117.

14. Dix P, Sandhar B, Murdoch J, MacIntyre PA. Pain on medical wards in a district general hospital. Br J Anaesth. 2004;92(2):235-237.

15. McGrath B, Elgendy H, Chung F, Kamming D, Curti B, King S. Thirty percent of patients have moderate to severe pain $24 \mathrm{hr}$ after ambulatory surgery: a survey of 5,703 patients. Can J Anaesth. 2004;51(9):886-891.

16. McNeill JA, Sherwood GD, Starck PL, Thompson CJ. Assessing clinical outcomes: patient satisfaction with pain management. J Pain Symptom Manage. 1998;16(1):29-40.

17. Mann E, Redwood S. Improving pain management: breaking down the invisible barrier. Br J Nurs. 2000;9(19):2067-2072.

18. Summers S. Evidence-based practice part 3: acute pain management of the perianesthesia patient. J Perianesth Nurs. 2001;16(2):112-120.

19. Warfield CA, Kahn CH. Acute pain management. Programs in US hospitals and experiences and attitudes among US adults. Anesthesiology. 1995;83(5):1090-1094.

20. McHugh GA, Luker KA, Campbell M, Kay PR, Silman AJ. A longitudinal study exploring pain control, treatment and service provision for individuals with end-stage lower limb osteoarthritis. Rheumatology (Oxford). 2007;46(4):631-637.

21. Donovan BD. Patient attitudes to postoperative pain relief. Anaesth Intensive Care. 1983;11(2):125-129.

22. Gan TJ, Lubarsky DA, Flood EM, et al. Patient preferences for acute pain treatment. Br J Anaesth. 2004;92(5):681-688.

23. Brown AK, Christo PJ, Wu CL. Strategies for postoperative pain management. Best Pract Res Clin Anaesthesiol. 2004;18(4):703-717.

24. Power I, Barratt S. Analgesic agents for the postoperative period: nonopioids. Surg Clin North Am. 1999;79(2):275-295.

25. Stephens J, Laskin B, Pashos C, Pena B, Wong J. The burden of acute postoperative pain and the potential role of the COX-2-specific inhibitors. Rheumatology (Oxford). 2003;42(Suppl 3):iii40-iii52.

26. McGettigan P, Henry D. Cardiovascular risk and inhibition of cyclooxygenase: a systematic review of the observational studies of selective and nonselective inhibitors of cyclooxygenase 2. JAMA. 2006;296(13):1633-1644.

27. Nicholson B. Responsible prescribing of opioids for the management of chronic pain. Drugs. 2003;63(1):17-32.

28. Shang AB, Gan TJ. Optimising postoperative pain management in the ambulatory patient. Drugs. 2003;63(9):855-867.

29. Chevlen E. Opioids: a review. Curr Pain Headache Rep. 2003;7(1):15-23.

30. Herndon CM, Jackson KC II, Hallin PA. Management of opioidinduced gastrointestinal effects in patients receiving palliative care. Pharmacotherapy. 2002;22(2):240-250. 
31. Wheeler M, Oderda GM, Ashburn MA, Lipman AG. Adverse events associated with postoperative opioid analgesia: a systematic review. J Pain. 2002;3(3):159-180.

32. Aparasu R, McCoy RA, Weber C, Mair D, Parasuraman TV. Opioidinduced emesis among hospitalized nonsurgical patients: effect on pain and quality of life. J Pain Symptom Manage. 1999;18(4):280-288.

33. Oderda GM, Evans RS, Lloyd J, et al. Cost of opioid-related adverse drug events in surgical patients. J Pain Symptom Manage. 2003;25(3): 276-283.

34. Oderda GM, Said Q, Evans RS, et al. Opioid-related adverse drug events in surgical hospitalizations: impact on costs and length of stay. Ann Pharmacother. 2007;41(3):400-406.

35. Tzschentke TM, Christoph T, Kögel B, et al. (-)-(1R,2R)-3(3-Dimethylamino-1-ethyl-2-methyl-propyl)-phenol hydrochloride (tapentadol $\mathrm{HCl}$ ): a novel $\mu$ opioid receptor agonist/norepinephrine reuptake inhibitor with broad-spectrum analgesic properties. J Pharmacol Exp Ther. 2007;323(1):265-276.

36. Tzschentke TM, De Vry J, Terlinden R, et al. Tapentadol HCl. Drugs Future. 2006;31(12):1053-1061.

37. Monory K, Greiner E, Sartania N, et al. Opioid binding profiles of new hydrazone, oxime, carbazone and semicarbazone derivatives of 14-alkoxymorphinans. Life Sci. 1999;64(22):2011-2020.

38. Hartrick CT. Multimodal postoperative pain management. Am J Health Syst Pharm. 2004;61(Suppl 1):S4-S10.

39. Reuben SS, Ekman EF, Charron D. Evaluating the analgesic efficacy of administering celecoxib as a component of multimodal analgesia for outpatient anterior cruciate ligament reconstruction surgery. Anesth Analg. 2007;105(1):222-227.

40. Terlinden R, Kögel B, Englberger W, Tzschentke T. In vitro and in vivo characterization of tapentadol metabolites. Methods Find Exp Clin Pharmacol. 2009; Submitted.

41. Kneip C, Terlinden R, Beier H, Chen G. Investigations into the drugdrug interaction potential of tapentadol in human liver microsomes and fresh human hepatocytes. Drug Metab Letters. 2008;2(1):67-75.

42. Wittwer E, Kern SE. Role of morphine's metabolites in analgesia: concepts and controversies. AAPS J. 2006;8(2):E348-E352.

43. Penson RT, Joel SP, Gloyne A, Clark S, Slevin ML. Morphine analgesia in cancer pain: role of the glucuronides. J Opioid Manag. 2005;1(2): 83-90.

44. Angst MS, Buhrer M, Lotsch J. Insidious intoxication after morphine treatment in renal failure: delayed onset of morphine-6-glucuronide action. Anesthesiology. 2000;92(5):1473-1476.
45. Osborne R, Joel S, Grebenik K, Trew D, Slevin M. The pharmacokinetics of morphine and morphine glucuronides in kidney failure. Clin Pharmacol Ther. 1993;54(2):158-167.

46. Armstrong SC, Cozza KL. Pharmacokinetic drug interactions of morphine, codeine, and their derivatives: theory and clinical reality, Part II. Psychosomatics. 2003;44(6):515-520.

47. Lotsch J, Skarke C, Liefhold J, Geisslinger G. Genetic predictors of the clinical response to opioid analgesics: clinical utility and future perspectives. Clin Pharmacokinet. 2004;43(14):983-1013.

48. Lotsch J, Skarke C, Tegeder I, Geisslinger G. Drug interactions with patient-controlled analgesia. Clin Pharmacokinet. 2002;41(1):31-57.

49. Smit JW, Oh C, Rengelshausen J, et al. Effects of acetaminophen, naproxen, and acetylsalicylic acid on tapentadol pharmacokinetics: results of two randomized open-label, crossover drug-drug interaction studies. Pharmacotherapy. 2010;30(1):25-34.

50. Daniels S, Casson E, Stegmann JU, et al. A randomized, double-blind, placebo-controlled phase 3 study of the relative efficacy and tolerability of tapentadol IR and oxycodone IR for acute pain. Curr Med Res Opin. 2009;25(6):1551-1561.

51. Daniels SE, Upmalis D, Okamoto A, Lange C, Haeussler J. A randomized, double-blind, phase III study comparing multiple doses of tapentadol IR, oxycodone IR, and placebo for postoperative (bunionectomy) pain. Curr Med Res Opin. 2009;25(3):765-776.

52. Hartrick C, Van Hove I, Stegmann JU, Oh C, Upmalis D. Efficacy and tolerability of tapentadol immediate release and oxycodone $\mathrm{HCl}$ immediate release in patients awaiting primary joint replacement surgery for end-stage joint disease: a 10-day, phase III, randomized, double-blind, active- and placebo-controlled study. Clin Ther. 2009;31(2):260-271.

53. Hale M, Upmalis D, Okamoto A, Lange C, Rauschkolb C. Tolerability of tapentadol immediate release in patients with lower back pain or osteoarthritis of the hip or knee over 90 days: a randomized, doubleblind study. Curr Med Res Opin. 2009;25(5):1095-1104.

54. McNicol E, Horowicz-Mehler N, Fisk RA, et al. Management of opioid side effects in cancer-related and chronic noncancer pain: a systematic review. J Pain. 2003;4(5):231-256.

55. Bell TJ, Panchal SJ, Miaskowski C, Bolge SC, Milanova T, Williamson R. The prevalence, severity, and impact of opioid-induced bowel dysfunction: results of a US and European Patient Survey (PROBE 1). Pain Med. 2009;10(1):35-42.

56. Benyamin R, Trescot AM, Datta S, et al. Opioid complications and side effects. Pain Physician. 2008;11(2 suppl):S105-S120.
Journal of Pain Research

\section{Publish your work in this journal}

The Journal of Pain Research is an international, peer-reviewed, open access, online journal that welcomes laboratory and clinical findings in the fields of pain research and the prevention and management of pain. Original research, reviews, symposium reports, hypothesis formation and commentaries are all considered for publication.

\section{Dovepress}

The manuscript management system is completely online and includes a very quick and fair peer-review system, which is all easy to use. Visit http://www.dovepress.com/testimonials.php to read real quotes from published authors. 